\title{
Contingent Expatriate Training Strategies with Examples of Taiwan MNEs
}

\author{
Hai-Ming Chen, Che-Cheng Chang \\ Department of Management Sciences, Tamkang University, Taiwan \\ Email: haiming@mail.tku.edu.tw, haimingchen1226@gmail.com, carmine.sky@msa.hinet.net
}

Received 15 December 2015; accepted 22 January 2016; published 25 January 2016

Copyright (C) 2016 by authors and Scientific Research Publishing Inc.

This work is licensed under the Creative Commons Attribution International License (CC BY). http://creativecommons.org/licenses/by/4.0/

c) (7) Open Access

\begin{abstract}
Expatriates play the critical role and are expected to demonstrate performances. Therefore, providing sufficient quantity and quality trainings to expatriates is critical for MNEs. With qualitative approach, this paper proposes four expatriate training strategies which consist of pre-departure training and supportive training for different internationalization situations after the literature review. We selected 4 presentative international companies from 2014 Outward Investment Directory of Taiwan as examples to explain four expatriate training strategies with different internationalization situations. We hope the contingent expatriate training strategies will facilitate MNEs to create and maintain competitive advantages.
\end{abstract}

\section{Keywords}

Component, Expatriate, Internationalization Situation, Training Strategy, Pre-Departure Training, Supporting Training

\section{Introduction}

In the current increasingly competitive era, multinational enterprises (MNEs) must frequently send internal employees to overseas subsidiaries to accomplish certain tasks and, thus, achieve corporate missions and strategic goals concerning internationalization. This practice, commonly referred to as expatriation, has gradually gained importance in the business activities of MNEs [1] or these companies, expatriate assignment has become an approach to maintain competitive advantages and success in response to global environmental changes [1]. Thus, expatriate management is a major concern in international human resource management (HRM), and expatriates play a critical role in the success of MNEs [2]. In addition to the tasks assigned by headquarters, expatriates are often responsible for being strategy "deliverers" or "connectors" between parent companies and their subsidiaries; therefore, the focus of employee competence development programs should be extended to consider the 
compatibility between expatriates and a firm's internationalization situation. When compatibility is greater, the performance of both the expatriates and the firm is more favorable. Because expatriates' adaptation to foreign environments and effective execution of assigned strategy are crucial for success, it is imperative that MNEs provide adequate training to prepare competent and adaptable expatriates.

Previous research on expatriation has focused on the selection and performance of expatriates or the factors that influence the adaptability of expatriates. Extant research on expatriate training has only determined the causal relationships between expatriate training and adaptation [3]. However, studies have reported that international businesses commonly experience expatriate failure and must bear the resulting cost, which can be substantial [4]. Hence, international businesses must build effective training programs to avoid these types of loss. In practice, expatriates must possess adequate professional skills as well as a thorough understanding of the company's internationalization situation. This study defines "training" as "any activity intended to systemically increase expatriates' knowledge, skills, and attitude necessary for performing a specific task or to develop their problem-solving ability" in pursuit of higher performance in other contexts [5]. Only by satisfying these requirements can expatriates effectively maintain the strategic relationships between parent companies and their subsidiaries. Black \& Mendenhall (1989) [4] explored cross-cultural training and planned training programs for two case companies. They suggested that expatriates may find follow-up training programs more useful after they have arrived at the overseas subsidiary. Therefore, we analyzed the characteristics of these four situations and constructed corresponding expatriate training strategies. The following methodological processes were employed: First, we synthesized and analyzed relevant literature to create a conceptual framework for expatriate training strategies corresponding to specific internationalization situations. Subsequently, the framework was illustrated based on four case examples. Four cases were chosen from the Outward Investment Directory (published by the Investment Commission, Ministry of Economic Affairs, Taiwan); each case corresponded to a specific internationalization situation as the corporate information and white paper disclosed. We then conducted in-depth interviews with the upper management personnel, HR personnel, and expatriates to understand the employed expatriate training strategies. Finally, we analyzed how the actual cases correspond to the proposed framework.

\section{Literature Review}

\subsection{Internationalization}

Perlmutter (1969) [6] introduced the concepts of "global strategy" and "international strategy". Prahalad and Doz (1981) [7] proposed a more substantive typology of MNEs and developed the "Global Integration—Local Responsiveness" framework. This became a prominent framework in the subsequent development of internationalization strategies and comprises two dimensions: pressure for global integration and pressure for local responsiveness [8]. Global integration is a strategy that focuses on the similarity in preferences among customers worldwide whereas local responsiveness is the degree to which multinational subsidiaries are responsive to local governments and consumer demands. This research employed the typology and the identifying concepts of the two dimensions to construct four internationalization situations based on two levels of pressure (high and low) for each of the two dimensions, and derive management implications for each situation.

\subsection{Human Resource Strategies}

In the area of HRM, substantial research has been dedicated to topics concerning HRM and corporate strategies [9] [10]. However, research dedicated to developing international human resources (HR) training strategies based on internationalization situations is rare. Schuler et al. (1993) [11] expounded their perspectives on a series of HR issues, including functions, policies, and practices. They suggested that MNEs must balance the needs of their subsidiaries to cope with implications of their differing contexts, including geographic settings. A MNE may encounter numerous ethnic and cultural barriers when it extends the operation of the headquarters' HRM system to overseas subsidiaries [12]. Hence, internationalizing businesses typically use expatriates to ensure that the parent company's policies are fully implemented among all subsidiaries.

From a long-term perspective, organizational environments comprise internal and external environments. Internal environments belong to organizational resource allocation patterns, whereas the position of organizations within a competitive market is considered in discussions of external environments [13]. The status of organiza- 
tional resource allocation and competitive advantages can change rapidly; therefore, strategies should be adjusted in consideration of various internal and external environments. To facilitate attaining competitive advantages, HRM must focus on developing strategies that are supported by organizational goals, visions, culture, and other functional strategies [14].

In our research, we contend that organizations have diverse resources and encounter various situations [15]. The contingency approach plays a vital role in organizational strategies, particularly in HR strategies [16] [17]. In addition, HR strategies are the primary source from which organizations attain competitive advantages [18] [19]. HR strategies include numerous functional strategies such as recruitment and selection, performance appraisal, compensation, and training and development strategies [20] [21]. Thus, an effective expatriate training program is designed according to the characteristics of the internationalization situation faced by the company. In other words, in the development of an expatriate training program, management should consider the core strategy used by the company according to the internationalization situation and incorporate the focuses of this strategy into training to ensure that training conforms to the strategic goals and task requirements of the company.

Taiwan is known for being remarkably innovative and exhibiting the highest level of industrial clustering worldwide. Taiwan is also the most suitable place in the Asia-Pacific region for transnational companies to establish headquarters. According to the 2014 IMD World Competitiveness Yearbook, Taiwan ranks 13th by world competitiveness and Taiwanese MNEs are world leaders. It is crucial to understand how Taiwan's MNEs firms respond to different international situations as this study provided.

\subsection{Expatriate Training Strategies}

Firms engaged in internationalization frequently send a portion of their staff to live and work overseas and plan to repatriate these expatriates to maintain their internationalization and globalization operations. Expatriates are defined as employees of business organizations who are sent overseas temporarily to complete a time-based task or accomplish an organizational goal [3]. Expatriates can be divided into two types: organizationally-assigned and self-initiated. In recent years, self-initiated expatriates have become the object of a growing number of studies. The term "self-initiated expatriates" refers to employees who voluntarily accept an overseas job assignment [22]. They generally consider expatriation as an indispensable part of their career, are highly committed to the overseas assignment, and demonstrate high performance [22]-[24]. However, both types of expatriate are crucial for MNEs in the development and operation of overseas businesses [25]. Provided with adequate training, expatriates can identify their goals in overseas assignments and overall achieve higher performance, as well as demonstrate their aptitude in adapting to the overseas environment [4] [26]. Studies have suggested that professional knowledge and skills that are essential for expatriates should be incorporated into employee training [27]. Tung (1981) [28] identified six major types of cross-cultural training. Furthermore, Forster (2000) [26] indicated that pre-departure training and briefings can facilitate expatriates' adaptation to work and life in a new environment.

Black and Mendenhall (1989) [4] asserted that expatriate training can be provided using three methods: factual, analytical, and experiential methods. Factual methods involve using briefings, lectures, and books to introduce the culture of the host nation; analytical methods involve using films, case studies, indoor language training, and sensitivity training; and experiential methods entail cultural training provided through role plays, interactive language training, and field trips. Odenwald (1993) [29] proposed an expatriate training program composed of various types of training, including cultural awareness, multicultural communication, country-specific, and host-country workforce training as well as executive development and language courses. Harrison (1994) [30] divided expatriate training into two stages, namely general orientation and specific development. The first stage consists of two phases, namely self-assessment and cultural awareness, and the second stage also consists of two phases, namely knowledge acquisition and skills training. Harrison (1994) [30] mentioned that, in addition to increasing the functional effectiveness of expatriates, a comprehensive training program prepares expatriates for positive cross-cultural experiences.

Tung (1981) [28] designed expatriate training from the contingency view but did not further investigate how post arrival training should be provided. Another study considered the idea of follow-up training [4] but did not design expatriate training methods for specific internationalization situations from the contingency view. Expatriates are expected to perform the duty of transferring knowledge from the parent company to the subsidiaries and assist in the management of subsidiaries operating in the context of global competition [25]. Luthans and Hodgets (1991) [31] suggested that expatriate training facilitates communications between the parent company 
and subsidiaries. Provided with sufficient training, expatriates can adequately represent any given international status of the parent company, and implement its mission in the process. Therefore, it is suggested that appropriately designed training can increase the competence of expatriates and allow them to contribute to the accomplishment of the common goals shared by the headquarters and subsidiaries.

Previous research has indicated that expatriate training assists expatriates in quickly enhancing their cultural sensitivity and cross-cultural communication ability [32], developing the core competencies required to perform their assignments, and applying acquired skills in practical work to accomplish expected goals [26]. However, contingency view suggests that there is no single optimal method for achieving expected performance, and the fit between external conditions and internal factors is the fundamental determinant of performance [33]. Providing expatriates with sufficient and effective training is crucial for MNEs [34]. To our knowledge, previous research didn't develop expatriate training combined with pre-departure and supportive training, entirely based on different internationalization situations in contingency view. Hence, we analyzed the characteristics of these different internationalization situations and construct corresponding expatriate training strategies.

\section{Research Method}

First, we synthesized and analyzed relevant literature to create expatriate training strategies corresponding to specific internationalization situations. Then four cases were discussed to find if the practice is different from the strategies we developed. Case discussion is a method for investigating a subject with specific attributes whereby crucial, subject-specific data can be conceptualized as past or ongoing events for analysis by the researcher. In this study, we performed case matching of data that involved concepts and ideas that could not be described in figures but only in words (e.g., training focuses, meanings of the training). We believe that this method produces more accurate results than the survey method and offers profounder implications for corporate policies.

Four MNEs were chosen from the Outward Investment Directory (published by the Investment Commission, Ministry of Economic Affairs, Taiwan); each enterprise corresponded to a specific internationalization situation as the corporate information and white paper disclosed. The measurement of global integration was based on two Likert scale items identified: “The parent company has centralized many functions such as R\&D, finance, and procurement" and "The parent company has, to a high extent, standardized products and services worldwide”. The measure of local responsiveness was also based on two Likert scale items: “The firm conducts many major functions locally" and "The firm has adopted its products and services to a high degree to the local context” [35]. We subsequently contacted each of these companies to inquire whether they were willing to participate in our research. To ensure the representativeness of this study, the companies that we selected had a capital exceeding NT\$100 million. Not all of the companies were willing to participate in our research and provided substantive information about their company. Therefore, for each internationalization situation, we identified one enterprise that was the most representative and from which we could obtain more information.

Company M-Makalot Industrial CO. LTD., the leading enterprise in the Taiwan textile industry, exhibited low levels of global integration and local responsiveness. Company B-Hexapals CO. LTD., a plastic material trading company that was initially established in Taiwan and now operates in Mainland China, exhibited a low level of global integration and a high level of local responsiveness. Company F-Foxconn Electronics Inc., a large technology group in Taiwan that conducts vertical integration activities worldwide to increase economies of scale with high levels of global integration but exhibited a low level of local responsiveness. Finally, Company G-Dachan Food (Asia) Limited in Great Wall Group, a large multinational food group company, exhibited high levels of global integration and local responsiveness.

By conducting in-depth interviews with managers (CEO \& HR manager) who familiar with expatriate training strategies, HR personnel who developed and executed the expatriate training programs, and expatriates who had or intended to work overseas, we identified the expatriate training concepts and methods of the four MNEs, studied the content of pre-departure training and expatriate training programs, and examined the cognition, attitudes, and training requests of expatriates. The entire semi-structured interview lasted 1 to 2 hr. Each interview was arranged and confirmed by mail or telephone. Most of the interviews were conducted in cafés, outside the MNEs of each respondent; the respondent answered our questions at ease and with little noise disturbance. Each interview was recorded with the consent of the respondent and transcribed verbatim on-site.

Based on the research objective we prepared an interview guideline. However, during the interviews, we did not merely follow the guideline or restrict the respondents to answer only to the questions. We were unpreju- 
diced and allowed each respondent to provide elaborate answers to our questions using their own language, logic, and linguistic structure. Depending on their responses, we probed further or adjusted our questions. Asking open-ended questions allowed us to understand the goals and practices of expatriate training in each enterprise.

\section{Research Results: Contingent Expatriate Training Strategies}

Previous research has shown that approximately $70 \%$ of MNEs provide training courses at least one day in duration to their expatriates [36]. Although expatriate training is widely considered crucial among businesses, the duration, depth, and breadth of the expatriate training programs of most businesses remain insufficient [36]. Most extant research of expatriate training tends to focus on pre-departure training and seldom addresses onthe-job training or organizational support that expatriates need during assignment. This paper proposes supportive training with logical implications and suggests that supportive training be used in collaboration with the pre-departure primary training to fill the insufficiencies of the primary training. The contingency view asserts that organizations should not rely on rigid operational strategies; conversely, they should adapt their strategies according to the environment. Therefore, expatriate training strategies should be adjusted according to organizational environments to create competitive advantages [37]. We involved identifying the contexts of various internationalization situations to develop training strategies for expatriates by considering environmental changes.

This study utilizes the two dimensions: pressure for global integration and pressure for local responsiveness and classified the degrees of global integration and local responsiveness into "high" and "low", as suggested by and Ghoshal (1989) [8], to develop four internationalization situations, each of which entails a corresponding expatriate training strategy. The expatriate training strategies are presented in Figure 1.

In this paper, expatriate training comprises two aspects: 1) training in cross-cultural or individual competences, and 2) developing the knowledge of organizations' international strategic directions and interactions with local organizations and networks; additionally, pre-departure training and supportive training during assignments are also included. Pre-departure training is defined as relevant training provided to expatriates before they depart for their assigned international destinations for work. In addition, supportive training is defined as the assistive or supportive training content provided to expatriates during their assignment overseas. The proposed expatriate training is long-term, multifaceted, and systematic. This training continues and strengthens the predeparture training previously completed by the expatriates, and successfully guides the expatriates in their roles and tasks. The strategies this study proposed can help MNEs develop an appropriate training strategy that corresponds to the internationalization situations.

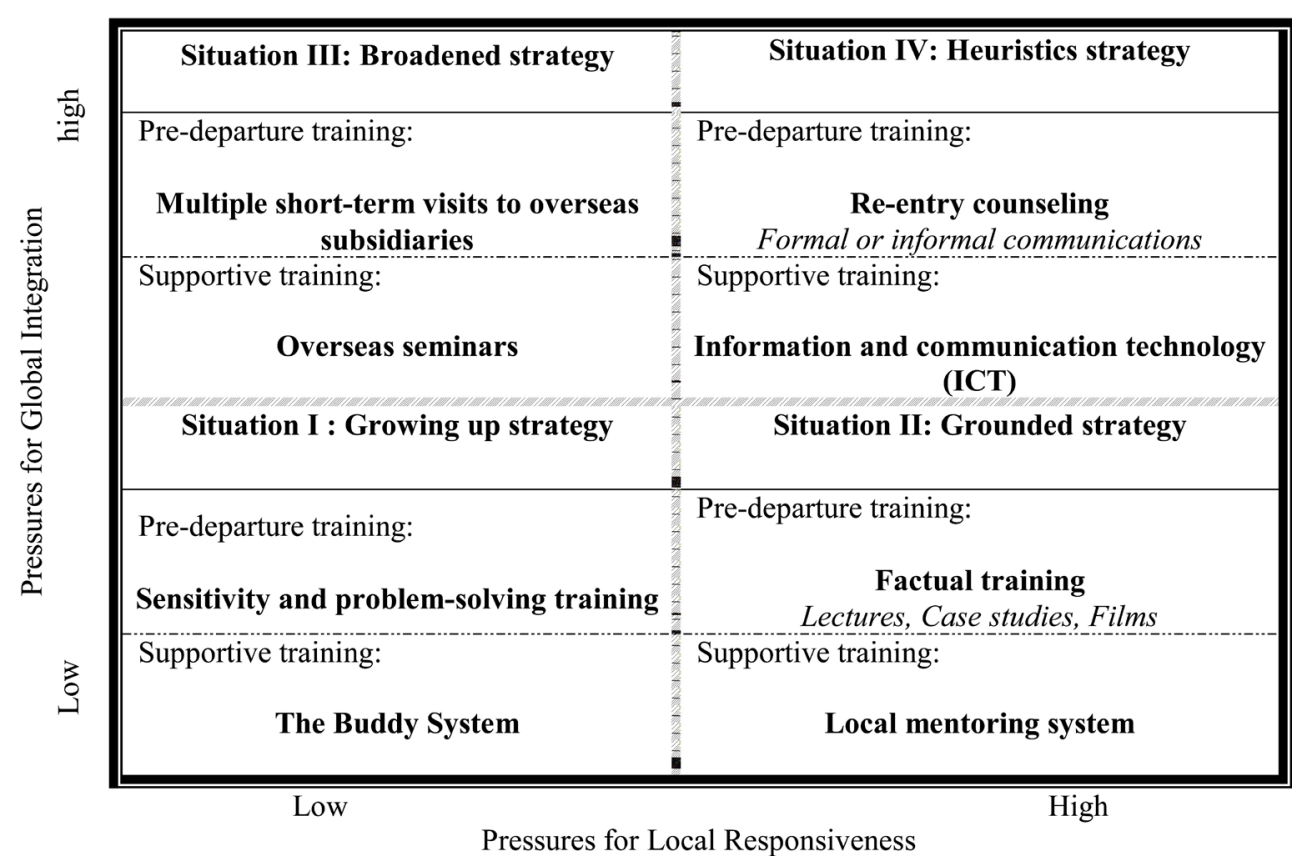

Figure 1. The contingent expatriate training strategies. 


\subsection{Situation I: The Growing-Up Strategy}

In Situation I, firms exhibit low levels of global integration and local responsiveness. Firms do not pay a substantial amount of attention to global uniformity or regional differences. MNEs transfer the knowledge, abilities, products, processes, and strategies of the parent company to less developed overseas markets. The core of the strategy is adequate transfer of key resources and abilities from the parent company to subsidiaries and subsidiaries' independent development of resources and abilities required for the local market. The growing-up strategy corresponds with Situation I.

The growing-up strategy entails providing sensitivity and problem-solving training as pre-departure training and applying the buddy system in supportive training. This strategy consists of a series of training sessions during which expatriates role play the supervision of subsidiaries and communication with parent companies. The growing-up strategy enables MNEs in Situation I to develop global uniformity; regional differences are not highly stressed, the parent company is usually responsible only for crucial decisions, and subsidiaries are authorized to make decisions regarding local activities [8]. Connelly, Hitt, DeNisi and Ireland (2007) [38] stated that it creates value by transferring core competencies and resources from headquarters to foreign markets. Subsidiaries are allowed a low level of autonomous decision making and are responsible for a limited scale of customized production. In other words, the parent company does not have centralized control over subsidiaries, and subsidiaries do not expect to be sufficiently directed in all decisions by the parent company.

\subsubsection{The Pre-Departure Training in Situation I: Sensitivity and Problem-Solving Training}

In Situation I, expatriates from the parent company play a critical role. They must supervise subsidiaries on behalf of the parent company and assist subsidiaries in improvement and self-governance. In addition to having outstanding management and professional skills, expatriates must be sensitive to others, possess an ability to detect problems in subsidiaries, and immediately react to these problems. Therefore, as suggested by Tung (1981) [28], Dowling and Schuler (1990) [39], and Shih et al. (2005) [2], firms that adopt this strategy should hire professional instructors to provide sensitivity training to their expatriates. In addition, expatriates can develop the problem-solving abilities of discernment and judgment after undergoing training in exploring problems, analyzing problems, and identifying solutions. All of these skills can strengthen expatriates' sensitivity, problem-solving ability, and competence in cross-cultural communication before expatriating.

\subsubsection{The Supportive Training in Situation I: The Buddy System}

The headquarters of firms in Situation I do not completely intervene in the decision making of subsidiaries while transferring a portion of core competence to them. Subsidiaries are allowed a low level of independent development. This close yet distant relationship between headquarters and subsidiaries causes effective support and assistance from the parent company to be indispensable. Thus, the buddy system introduced by Gomez-Mejia, Balkin and Cardy (1998) [40] is a supportive training mechanism that can facilitate communication and interaction between expatriates and the parent company. The parent company assigns one counselor or manager as the contact between the companies and expatriates. This counselor must contact the expatriates weekly to understand their progress and exchange current information with them. In addition, the counselor must make communication channels available during work hours to ensure that the expatriates can access necessary assistance immediately if they experience difficulty in accomplishing assigned tasks.

In summary, subsidiaries in Situation I neither completely depend on the resources and control of their parent company nor have sufficient authorization to develop locally. Thus, expatriates must grasp independently the strategic scale or dimensions between the two. Expatriates must rely on their abilities to assess overseas situations and formulate immediate countermeasures. In addition, because subsidiaries are not permitted to develop a high degree of localization in Situation I, they must maintain some extent of contact and policy coherence (or consistency) with their parent company. Therefore, a growing-up strategy comprising sensitivity and problem-solving training and the buddy system is the most appropriate training method for addressing the characteristics and demands of Situation I.

Company M, the leading enterprise in the Taiwan textile industry, exhibited in Situation I with low levels of global integration and local responsiveness. We found that most expatriates in Company $\mathrm{M}$ were factory managers and deputy factory managers as well as specialists who were responsible for tracking and counseling work in the production and quality assurance department. This indicates that the parent company is responsible for 
supervising and assisting expatriates who promote the self-improvement and governance mechanisms of overseas subsidiaries. This meets the requirements for MNEs in Situation I to emphasize the transfer of knowledge, abilities, products, processes, and strategies from the parent company to subsidiaries. Hence, in addition to favorable managerial and professional skills, expatriates should have the ability to discern problems in overseas subsidiaries and react to the problems promptly. During pre-departure training, Company $\mathrm{M}$ describes to the expatriates the various tasks for which each department is responsible and all other company-operation-related details to which the expatriates must attend. In addition to teaching expatriates' management skills and how to use professional technologies, Company $\mathrm{M}$ provides expatriates with information regarding the overseas subsidiaries to enhance employee response capabilities and ensure that the expatriates become familiar with the overseas working environment quickly. These expatriate programs corresponded with the growing-up strategy proposed to address Situation I.

\subsection{Situation II: The Grounded Strategy}

In Situation II, MNEs maximize local responsiveness [38]. Each subsidiary is considered an independent business entity and is allowed to react to regional differences, such as customer preferences, business characteristics, and regulations, to satisfy the diverse needs of the local market flexibly. Thus, the grounded strategy is the expatriate training strategy most suited to the characteristics of Situation II.

The grounded training strategy begins with factual pre-departure training and entails applying the local mentoring system in supportive training. This training strategy consists of a series of trainings that guide expatriates in flexibly operating the regions of subsidiaries.

\subsubsection{The Pre-Departure Training in Situation II: Factual Pre-Departure Training}

Firms that adopt a localization strategy in situation II should stress responsiveness to local market preferences and independent governance of subsidiaries in expatriate training and should provide more factual training to their expatriates by using books, briefings, lectures, films, and case studies about the subsidiary. Moreover, increasing expatriates' knowledge regarding the laws and regulations of the host nation is essential for fulfilling the localization strategy. After gaining a preliminary understanding of the local environment, customers, and political situations, expatriates can effectively act according to the culture and preferences of the local market. Firms in Situation II should begin by acquiring local information and, subsequently, adapt to the local environment. Finally, they should realize Harzing's (2000) [41] concept of local responsiveness: "know, adapt, and respond to local needs” before expatriating.

\subsubsection{The Supportive Training in Situation II: The Local Mentoring System}

The grounded training strategy entails applying the local mentoring system in supportive training. Because expatriates may be incapable of managing special conditions in the host nation without extensive background knowledge, a local mentoring system plays a vital role in supporting expatriates. Well-experienced employees at subsidiaries can mentor expatriates. Familiar with the local market and job-relevant information; these well-experienced employees can assist expatriates in coping with various problems that they encounter in the host nation. Aycan (1997) [42] suggested that senior employees can guide expatriates in becoming involved in the local culture, understanding the ideas and behavior of local people, establishing interpersonal and cooperative relationships, and coordinating technical and management aspects. We referred to senior local employees as well-experienced employees, not necessarily as higher-ranking employees. According to the social support perspective, support from organizations, supervisors, colleagues, family members, or friends is an interpersonal transaction involving emotional concern, instrumental assistance, information, or appraisal [43]. When provided with the necessary resources and assistance, the impacts of burnout caused by job stress can be mitigated, thus achieving higher job performance [44]. Assistance from well-experienced employees also can prevent the power distance.

In summary, when expatriates undergo factual training, an in-depth local understanding should be the starting point; the local mentoring system should be implemented in a supportive training method once expatriates arrive at their assigned subsidiary. Through the immediate assistance of a local mentor, expatriates can strengthen their competence in local management and formulate appropriate local response policies. Therefore, using a grounded training strategy comprising factual training and the use of a local mentoring system facilitates the development of foundations overseas and the execution of localized management concepts. Therefore, this strategy is the 
most suited to the characteristics of Situation II.

Company B exhibited in Situation II with low level of global integration and high level of local responsiveness. The enterprise has been trading and selling plastic materials in Taiwan for many years and complied with the local laws and market culture when expanding their business in Kunshan and Shenzhen, Mainland China. Company B provides one month of basic sales training to expatriates before departure to reinforce their knowledge about the products. By conducting an in-depth interview with the deputy sales manager based in the subsidiary in Kunshan, we determined that the expatriates in Mainland China are primary responsible for attracting new customers and retaining purchase orders from existing customers. Therefore, the enterprise primarily provides basic sales training as pre-departure training for expatriates. The management department schedules programs and asks the deputy manager of each region to introduce products to the newly recruited expatriates and explain the use of various products, emergency management, and post-sale problem management. The experienced staff members in each region accompany newly expatriates when visiting customers to ensure that the expatriates learn how to manage customer concerns effectively during their visits. Finally, local suppliers and subsidiaries continually offer education and training during expatriation periods, providing information regarding the development and introduction of new products, product information, and updates regarding local competitors. Therefore, parent company employ the fact-giving method by providing books, speeches, and introductory information regarding the host countries during pre-departure training, thereby assisting expatriates in fully understanding market preferences and the local culture and adapting and responding to local demands. These expatriate training programs correspond to the grounded strategy proposed for Situation II. The training goal of Situation II, requires firms to begin with “acquiring local information” followed by "adapting to the local environment" and finally implement the concept of "local responsiveness". Researchers also suggest that Company B should implement the proposed mentoring system. Experienced staff members at local subsidiaries should mentor expatriates when addressing challenges in host countries, thereby enhancing the knowledge of newly expatriates regarding the host countries and enriching their experiences.

\subsection{Situation III: The Broadened Strategy}

In Situation III, firms treat the world as largely one market and are concerned with the global efficiency of each product to maximize globalization. They rely on the economies of scale of their global production to remain competitive in the market. Strategies are largely centralized and firm resources and assets are completely controlled by the parent company. Subsidiaries can be integrated, but most of the core techniques of the firm are kept in the home country. The broadened strategy corresponds with Situation III.

The broadened strategy involves providing pre-departure training through multiple short-term visits to various subsidiaries and providing supportive training through overseas seminars. This strategy consists of a series of training sessions that enable expatriates to integrate global goals and to control subsidiaries in response to Situation III. Firms adopting the broadened strategy attempt to integrate the most favorable aspects of all countries into one corporate culture. They use the international experience of managers by placing these managers in senior positions [45]. The expatriate training of these firms must emphasize effective integration and control.

\subsubsection{The Pre-Departure Training in Situation III: Multiple Short-Term Visits}

Expatriates in Situation III are expected to coordinate and integrate the tasks of subsidiaries can be assigned to short-term business trips as part of their training. Packer and Ballantyne (2004) [46] indicated that various fields support learning. Learning components can be introduced to promote learning in any environment where it is easy to elicit participants' curiosity to explore. Previous research has also shown that planned visits can be used to experience different cultures in other countries to understand the cultural background of local people and even develop new knowledge or interest [47]. Black and Mendenhall (1988) [4] documented that the case company 1-Wave designed numerous training programs, including the program "pre-move visit to Japan.” In addition, visits motivated by learning can produce longer-lasting outcomes [48], so multiple short-term visits to various subsidiaries can serve as pre-departure training for expatriates. Through this training, expatriates can accumulate experience at various subsidiaries and knowledge of the culture and environment of the host nation. Because they have met and worked with the staff at different subsidiaries before assignment, they have sufficient familiarity with the operating conditions and the staff of the subsidiary from a global perspective. With experiences of these short-term trips, expatriates become more adaptable to the new environment and exhibit greater compe- 
tence in achieving global tasks when they are assigned to work at an overseas subsidiary for a longer period of time. Therefore, the short-term visits provide a realistic preview of subsidiaries.

\subsubsection{The Supportive Training in Situation III: Overseas Seminars}

Because the expatriates of enterprises in Situation III must perform control and integration tasks, innovative training suggested by Lasserre's (1982) [49] can be followed to organize groups containing more knowledge deliverers and receivers, thereby facilitating interaction and mutual learning. Therefore, overseas seminars can be held regularly to encourage the participation of expatriates. By increasing interaction between expatriates and the parent company, firms can ensure that their policies are implemented at subsidiaries. By organizing social activities for expatriates, firms can facilitate communication and interaction between expatriates posted at subsidiaries in various nations. Expatriates can improve their competence through opportunities to share management skills and professional techniques. Furthermore, overseas seminars enable expatriates to understand the operations of other subsidiaries; this understanding is critical to the formation of a cooperative relationship between subsidiaries.

In summary, parent companies in Situation III adopt a centralized approach to integrate interdependent subsidiaries or globally dispersed business units, which require substantial resource sharing and cooperation. Consequently, expatriates sent abroad assume the corporate missions, and internal high-level personnel are typically responsible for coordinating and integrating the subsidiaries in various areas to ensure effective integration and control. Furthermore, expatriates can be assigned to multiple short-term business trips to various subsidiaries as part of the pre-departure training of a broadened strategy. Furthermore, overseas seminars can be provided as supportive training to assist expatriates in effectively increasing their competence in coordinating and integrating tasks overseas. Therefore, a broadened training strategy comprising multiple short-term visits and overseas seminars is highly appropriate for the expatriates of firms in Situation III.

Company F, a large technology group in Taiwan exhibited in Situation III with high levels of global integration. Management members of the enterprise receive 6 months of training on the product lines before being sent to overseas subsidiaries to execute their assigned tasks and receive little support training during their expatriation periods. The interviewee had been sent to overseas subsidiaries on numerous occasions to reinforce the technology development and technology transfer objectives stressed by the parent company and to improve the production quality of the overseas subsidiaries. The parent company sent specialists responsible for quality assurance. This indicates that the core techniques of the firm are mostly retained in the home country and subsidiaries are more integrated. The expatriates in Company $\mathrm{F}$ were required to perform control and integration tasks, therefore they required more innovation competence. This strategic method aligned with the global strategy, which emphasized comprehensiveness and consistency. Moreover, the enterprise sends expatriates to each overseas subsidiary to conduct surveys and provide counseling; this practice is consistent with the proposal that expatriates engage in short-term visits as the broadened strategy of Situation III. We also suggest that Company F implement overseas seminars as supportive training.

\subsection{Situation IV: The Heuristic Strategy}

Situation IV emphasizes how regional or market differences can be used as a foundation for learning and innovation and how the differences can be translated into resources and abilities that can be exploited worldwide. Firms in this situation intend to form an interconnected network of subsidiaries to facilitate sharing and the innovation of resources, knowledge, and abilities. According to Connelly et al. (2007) [38], a firm seeks to lower its costs while responding to local demands. Thus, the firm seeks an optimal balance between global coordination and flexibility as well as local control. In short, it must achieve a high level of global integration of the subsidiaries and simultaneously allow a high level of autonomous operation. In addition, Connelly et al. (2007) [38] argued that firms assume global responsibility for a set of value-creating activities associated with a specific product or service. The heuristics training strategy corresponds with Situation IV.

The heuristics training strategy entails applying reentry counseling in pre-departure training and information and communication technology (ICT) in supportive training. This strategy consists of a series of training sessions designed to improve expatriates' competence, knowledge management, and sharing. Heuristics training strategy is suited to Situation IV because global uniformity and regional differences are both emphasized. The parent company is not the only source of competitive advantages; conversely, each subsidiary can develop its 
unique abilities to enhance the competitive advantages of the firm [8]. The role of expatriates is multifaceted, nonprogrammable, knowledge intensive, and concerned with local innovation. In information sharing and resource interdependence, the expatriates of transnational firms must emphasize the development of knowledge and skills.

\subsubsection{The Pre-Departure Training in Situation IV: Reentry Counseling}

In consideration of the fact that firms rely heavily on knowledge sharing to address Situation IV [8] [38], we suggest that a firm's experienced repatriates serve as lecturers in reentry counseling, as mentioned by Bryant (2005) [50]. Through formal or informal communication channels in reentry counseling, experienced repatriates can impart their practical experiences and the knowledge that they have accumulated over a long period of time to future expatriates. According to Bryant (2005) [50], reentry counseling is to invite repatriates to deliver a series of reports on the experiences and difficulties they encountered during their overseas assignment. This activity allows the company to understand the problems faced by expatriates and modify their expatriate management policies accordingly. Therefore, we suggest companies invite not only repatriates but also intending expatriates to reentry counseling. They can use this opportunity to allow repatriates to share their experiences with intending expatriates (trainees). We believe intending expatriates can benefit from the advice and know-how of the repatriates. This form of reentry counseling can serve as pre-departure training for expatriates.

\subsubsection{The Supportive Training in Situation IV: ICT}

In addition, parent companies should externalize knowledge by organizing the knowledge and experience of expatriates in a database and promoting the use of ICT among expatriates. Expatriates are advised to browse data in this database for at least one hour each week as a part of their supportive training. This database containing critical knowledge can be a crucial resource when expatriates encounter difficulty at work and must quickly obtain information for use as a foundation for developing solutions. Through this internal knowledge-cycling mechanism, MNEs can achieve knowledge sharing and dissemination within the organization. We advise MNEs in Situation IV to create an atmosphere fostering knowledge sharing and information communication among employees. Through interaction, employees can progressively implement e-learning using ICT and establish it as a primary learning model [51] [52]. Any form of e-learning can provide trainees with the resources and support necessarily for analyzing and solving problems. In the process of observing a solution, trainees will construct knowledge and develop a competence in problem solving [53] or identify the scope of the problem based on the available information. ICT offers data and functions that can compensate for the deficiencies in the knowledge, competence, or experience of trainees, helping them enhance their knowledge when pursuing solutions [54]. In addition, as suggested by Carruth (2007) [55] and Netteland et al. (2007) [56], MNEs should analyze the needs of trainees in-depth and design the training topics, materials, and schedule accordingly.

Each subsidiary in Situation IV can develop unique abilities to enhance the competitive advantages of the firm. Therefore, according to these characteristics and the training objective of managing and sharing knowledge, a heuristic training strategy comprising reentry counseling and ICT use is appropriate for addressing the demands of Situation IV.

Company G, a large multinational food group company, exhibited in Situation IV with high levels of global integration and local responsiveness. The enterprise established a comprehensive KM online education system for newly recruited employees. For expatriates, the company offers $2 \sim 4$ weeks of pre-departure training. By conducting an in-depth interview with a sales manager who had experience as an expatriate, we determined that the enterprise primarily sends expatriates to overseas subsidiaries to increase their international work experience in overseas markets. Therefore, during the $2 \sim 4$ weeks of pre-departure training, the company focuses on providing training on local laws, HR administration and systems, sales, management, interpersonal relationships, and finance to assist expatriates in working in future overseas jobs. Through the comprehensive KM online education system, Company $G$ also offers on-the-job training during expatriation periods, and constructed a knowledge base and shares knowledge with expatriates, thus exhibiting the high dependency on knowledge flow identified in Situation IV. The training programs implemented by the enterprise correspond to the heuristics strategy proposed to facilitate the sharing of knowledge by using information technology. This training content of Company $\mathrm{G}$ that enables the sharing of resources, knowledge, and abilities, as well as the development of innovation, is required to establish interconnected knowledge networks. It conforms to the characteristics of firms in Situation IV, as suggested by Bartlett and Ghoshal (1989) [8]. 


\section{Discussion and Conclusion}

Expatriates play a vital role in the international operations of an MNE. Expatriate management is a major focus of international HRM [2]. Previous research has revealed that MNEs invest more in expatriate managers than in any other staff members in the organization, including the chief executive officer [38]. This finding indicates the importance of expatriate training in expatriates' work performance. In this paper, expatriate training strategies tailored to four internationalization situations were proposed based on two dimensions: pressures for global integration and pressures for local responsiveness. This study explored the characteristics of the four situations to identify the job appeal and training requirements of expatriates and thus develop corresponding training strategies. The expatriate training strategies address the highest priorities to which parent companies must attend in training expatriates, enabling expatriates to execute overseas tasks and, thus, corporate internationalization to be achieved.

In addition to indispensable basic training procedures such as language training and environmental briefings, each expatriate training strategy contains pre-departure training and supportive training which are required by expatriates and are designed to address various situations. We considered pre-departure and working aboard as two time-periods to provide contingent expatriate strategies in four internationalization situations. We also described the adequacy of each expatriate training strategy regarding its corresponding internationalization situation. The results are valuable and contribute to existing research in expatriate training.

The growing-up strategy is the most suited to addressing low pressure for local responsiveness and low global integration. The growing-up strategy entails providing sensitivity and problem-solving training as pre-departure training and using the buddy system in supportive training. This training strategy conforms to the characteristics of the overseas operations of enterprises in Situation I. It exhibits a pronounced emphasis on the ability of expatriates to react to problems and utilize the availability of smooth communication channels between expatriates and the parent company. The grounded strategy was designed to address a need for thorough local responsiveness and low global integration pressure and involved offering factual pre-departure training and using the local mentoring system to provide supportive training. The goal of this strategy is the complete localization of expatriates. This strategy conforms to the needs of enterprises in Situation II for deeper penetration into the local market. The "explicit knowledge" that local experts and mentors offer during post arrival training can also be acquired from factual training such as pre-departure training in the grounded strategy. By contrast, the "tacit knowledge” and local knowledge delivered during post arrival training can be effectively substituted by using the local mentoring system as supportive training. The broadened strategy was designed to address low responsiveness to regional differences, a high level of global integration, and a high level of centralization of power and entailed providing pre-departure training through multiple short-term visits to various subsidiaries and supportive training through overseas seminars. This training strategy is intended to help expatriates to develop a global perspective and global social networks. It conforms to the needs of enterprises in Situation III for more effective implementation of policies established by the parent company. The heuristics strategy is the most applicable to a situation characterized by global uniformity and regional differences and entails applying reentry counseling in pre-departure training and ICT in supportive training. The goal of this expatriate training strategy is to facilitate convergence of knowledge and the barrier-free sharing of knowledge within the organization to enhance the expatriates’ ability to innovate.

To the practice of expatriate management, this study makes the following contributions. First, unlike other studies of expatriate management, which have mainly examined the causal relationships between expatriate factors and success, this study involves developing expatriate training strategies that feature tangible focuses and are designed to address for different internationalization situations. In this era, during which internationalization is increasingly prevalent, the expatriate training strategies developed in this paper and illustrated through Taiwan MNEs examples have considerable practical value. Second, regarding international HRM, this paper emphasizes continuity of expatriate training, suggesting that firms should provide pre-departure training to expatriates before their departure and offer supportive training while they are working and living abroad. Supportive training can increase expatriates' competence in working overseas and overcoming challenges. Third, this paper offers insights to enterprises in Situation I or a transition between situations. We intend for the proposed strategies to enable enterprises to increase the effectiveness of expatriate training and place greater value on expatriate training. Expatriate training cannot be omitted simply because of time or financial constraints.

As with any study, there are several limitations. First, expatriate training strategies were developed through an 
extensive literature review and illustrated through in-depth interviews with employees of Taiwan MNEs. In the future, researchers can verified the expatriate training strategies through quantitative analysis. Second, suggestions for expatriate training strategies designed to address each internationalization situation were provided from a contingency perspective without considering the maturity of firms' internationalization. Researchers can include variables such as the maturity of internationalization when executing the expatriate training strategies.

\section{References}

[1] Chien, T.C. and McLean, G.N. (2011) Intercultural Training for US Business Expatriates in Taiwan. Journal of European Industrial Training, 35, 858-873. http://dx.doi.org/10.1108/03090591111185556

[2] Shih, H.A., Chiang, Y.H. and Kim, I.S. (2005) Expatriate Performance Management from MNEs of Different National Origins. International Journal of Manpower, 26, 157-176. http://dx.doi.org/10.1108/01437720510597658

[3] Takeuchi, R., Shay, J.P. and Li, J. (2008) When Does Decision Autonomy Increase Expatriate Manager's Adjustment? An Empirical Text. Academy of Management Journal, 51, 45-61. http://dx.doi.org/10.5465/AMJ.2008.30696751

[4] Black, J.S. and Mendenhall, M. (1989) A Practical but Theory Based Framework for Selecting Cross-Cultural Training Methods. Human Resource Management, 28, 511-539. http://dx.doi.org/10.1002/hrm.3930280406

[5] Brouthers, K.D. ( 2002) Institutional Culture and Transaction Cost Influences on Entry Mode Choice and Performance. Journal of International Business Studies, 33, 203-221. http://dx.doi.org/10.1057/palgrave.jibs.8491013

[6] Perlmutter, H.V. (1969) The Tortuous Evolution of the Multinational Corporation. Practicing Manager, 17, 13-18.

[7] Prahalad, C.K. and Doz, Y.L. (1981) An Approach to Strategic Control in MNCs. Sloan Management Review, 22, 5-13.

[8] Bartlett, C.A. and Ghoshal, S. (1989) Managing Across Borders: The Transnational Solution. Harvard Business School Press, Boston.

[9] Decieri, H., Dowling, P.J. and Tayler, K.F. (1991) The Psychological Impact of Expatriate Relocation of Partners. The International Journal of Human Resource Management, 2, 377-414. http://dx.doi.org/10.1080/09585199100000074

[10] Pucik, V. and Saba, T. (1998) Selecting and Developing the Global versus the Expatriate Manager: A Review of the State-of-the-Art. Human Resource Planning, 21, 40-54.

[11] Schuler, R.S., Dowling, P.J. and DeCieri, H. (1993) An Integrative Framework of Strategic International Human Resource Management. International Journal Human Resource Management, 4, 717-764. http://dx.doi.org/10.1080/09585199300000056

[12] Jain, H.C., Lawler J.J. and Morishima, M. (1998) Multinational Corporation, Human Resource Management and HostCountry Nationals. The International Journal of Human Resource Management, 9, 553-566. http://dx.doi.org/10.1080/095851998340892

[13] Chen, H.L. (2005) A Competence-Based Strategic Management Model Factoring in Key Success Factors and Benchmarking. Benchmarking, 12, 364-382. http://dx.doi.org/10.1108/14635770510609033

[14] DeNisi, A.S. and Griffin, R.W. (2005) Human Resource Management. 2nd Edition, Houghton Mifflin Company, Boston.

[15] Delery, J.E. and Doty, D.H. (1996) Modes of Theorizing in Strategic Human Resource Management: Tests of Universalistic, Contingency, and Configurational Performance Predictions. The Academy of Management Journal, 39, 802835. http://dx.doi.org/10.2307/256713

[16] Boyd, B.K. and Salamin, A. (2001) Strategic Reward Systems: A Contingency Model of Pay System Design. Strategic Management Journal, 22, 777-792. http://dx.doi.org/10.1002/smj.170

[17] Lepak, D.P., Bartol, K.M.J. and Erhardt, N.L. (2005) A Contingency Framework for the Delivery of HR Practices. Human Resource Management Review, 15, 139-159. http://dx.doi.org/10.1016/j.hrmr.2005.06.001

[18] Chan, L.L.M., Shaffer, M.A. and Snape, E. (2004) In Search of Sustained Competitive Advantage: The Impact of Organizational Culture, Competitive Strategy and Human Resource Management Practices on Firm Performance. International Journal of Human Resource Management, 15, 17-35. http://dx.doi.org/10.1080/0958519032000157320

[19] Wolfe, R., Wright, P.M., and Smart, D.L. (2006) Radical HRM Innovation and Competitive Advantage: The Moneyball Story. Human Resource Management, 45, 111-126. http://dx.doi.org/10.1002/hrm.20100

[20] Budhwar, P.S., Luthar, H.K. and Bhatnagar, J. (2006) The Dynamics of HRM Systems in Indian BPO Firms. Journal of Labor Research, 27, 339-360. http://dx.doi.org/10.1007/s12122-006-1027-7

[21] Leat, M. and El-Kot, G. (2007) HRM Practices in Egypt: The Influence of National Context? International Journal of Human Resource Management, 18, 147-158. http://dx.doi.org/10.1080/09585190601068557 
[22] Borstorff, P.C., Harris, S.G., Field, H.S. and Giles, W.F. (1997) Who’ll Go? A Review of Factors Associated with Employee Willingness to Work Oversea. Human Resource Planning, 20, 9-40.

[23] Selmer, J. (1998) Expatriation: Corporate Policy, Personal Intentions and International Adjustment. International Journal of Human Resources Management, 9, 996-1007. http://dx.doi.org/10.1080/095851998340711

[24] Suutari, V. (2003) Global Managers: Career Orientation, Career Tracks, Life-Style Implications and Career Commitment. Journal of Managerial Psychology, 18, 185-207. http://dx.doi.org/10.1108/02683940310465225

[25] Bjorkman, I. and Lu, Y. (2000) The Management of Human Resources in Chinese-Western Joint Ventures. Journal of World Business, 34, 306-324. http://dx.doi.org/10.1016/S1090-9516(99)00021-8

[26] Forster, N. (2000) Expatriates and the Impact of Cross-Cultural Training. Human Resource Management Journal, 10, 63-78. http://dx.doi.org/10.1111/j.1748-8583.2000.tb00027.x

[27] Bennett, R., Aston, A. and Colquhoun, T. (2000) Cross-Cultural Training: A Critical Step in Ensuring the Success of International Assignments. Human Resource Management, 3, 239-250. http://dx.doi.org/10.1002/1099-050X(200022/23)39:2/3<239::AID-HRM12>3.0.CO;2-J

[28] Tung, R.L. (1981) Selection and Training of Personnel for Overseas Assignments. Columbia Journal of World Business, 16, 68-78.

[29] Odenwald, S. (1993) A Guide for Global Training. Training \& Development, 47, 23-31.

[30] Harrison, J.K. (1994) Developing Successful Expatriate Managers: A Framework for the Structural Design and Strategic Alignment of Cross-Cultural Training Programs. Human Resource Planning, 17, 17-35.

[31] Luthans, F. and Hodgetts, R.M. (1991) International Management. McGraw-Hill, New York.

[32] Mendenhall, M. and Oddou, G. (1985) The Dimensions of Expatriate Acculturation. Academy of Management Review, 10, 39-47.

[33] Lawrence, P. and Lorsch, J. (1967) Differentiation and Integration in Complex Organizations. Administrative Science Quarterly, 12, 1-47. http://dx.doi.org/10.2307/2391211

[34] Kemper, L.C. (1998) Global Training’s Critical Success Factors. Training \& Development, 52, 35-37.

[35] Meyer, K.E. and Estrin, S. (2014) Local Context and Global Strategy: Extending the Integration Responsiveness Framework to Subsidiary Strategy. Global Strategy Journal, 4, 1-19. http://dx.doi.org/10.1111/j.2042-5805.2013.01071.x

[36] Tungli, Z. and Peiperl, M. (2009) Expatriate Practices in German, Japanese, UK, and US Multinational Companies: A Comparative Survey of Changes. Human Resource Management, 48, 153-171. http://dx.doi.org/10.1002/hrm.20271

[37] Black, J.S. and Porter, L.W. (2000) Management: Meeting New Challenges. Great Buy Books, Lakewood.

[38] Connelly, B., Hitt, M.A., De Nisi, A.S. and Ireland, R.D. (2007) Expatriates and Corporate-Level International Strategy: Governing with the Knowledge Contract. Management Decision, 45, 564-581. http://dx.doi.org/10.1108/00251740710745016

[39] Dowling, P.J. and Schuler, R.S. (1990) International Dimensions of Human Resource Management. PWS-KENT Publishing Company, Boston.

[40] Gomez-Mejia, L.R., Balkin, D.B. and Cardy, R.L. (1998) Managing Human Resource. Prentice-Hall, Inc., Upper Saddle River.

[41] Harzing, A.W. (2000) An Empirical Analysis and Extension of the Bartlett and Ghoshal Typology of Multinational Companies. Journal of International Business Studies, 31, 101-120. http://dx.doi.org/10.1057/palgrave.jibs.8490891

[42] Aycan, Z. (1997) Expatriate Adjustment as a Multifaceted Phenomenon: Individual and Organization Level Predictors. The International Journal Human Resource Management, 8, 434-456. http://dx.doi.org/10.1080/095851997341540

[43] House, J.S. (1981) Work Stress and Social Support. Addison-Wesley, Reading.

[44] Gerloff, E.A. and Hoyt, J. (1999) Organizational Environment, Changing Economic Conditions, and the Effective Supervision of Technical Personnel: A Management Challenge. Journal of High Technology Management Research, 10, 275-293. http://dx.doi.org/10.1016/S1047-8310(99)00014-0

[45] Caligiuri, P. and Colakoglu, S. (2007) A Strategic Contingency Approach to Expatriate Assignment Management. Human Resource Management, 17, 393-410. http://dx.doi.org/10.1111/j.1748-8583.2007.00052.x

[46] Packer, J. and Ballantyne, R. (2004) Is Educational Leisure a Contradiction in Terms? Exploring the Synergy of Education and Entertainment. Annals of Leisure Research, 7, 54-71. http://dx.doi.org/10.1080/11745398.2004.10600939

[47] Bodger, D. (1998) Leisure, Learning and Travel. Journal of Psychology Education, Recreation \& Dance, 69, $28-31$. http://dx.doi.org/10.1080/07303084.1998.10605532

[48] Ryan, C. (1998) Playful Tourists: Constructs of Learning-A Commentary on Mitchell’s Learning through Play and 
Pleasure Travel: Using Play Literature to Enhance Research into Touristic Learning. Current Issues in Tourism, 1, 184-194. http://dx.doi.org/10.1080/13683509808667839

[49] Lasserre, P. (1982) Training: Key to Technological Transfer. Long Range Planning, 15, 51-60. http://dx.doi.org/10.1016/0024-6301(82)90026-7

[50] Bryant, E.S. (2005) The Impact of Peer Mentoring on Organizational Knowledge Creation and Sharing. Group and Organizational Management, 30, 319-339. http://dx.doi.org/10.1177/1059601103258439

[51] Morch, A.I., Engen, B.K. and Asand, H.-R.H. (2004) The Workplace as a Learning Laboratory: The Winding Road to E-Learning in a Norwegian Service Company. Paper Presented at the 8th Conference on Participatory Design, Toronto, 27-31 July 2004, 142-151. http://dx.doi.org/10.1145/1011870.1011888

[52] Murphy, S. (2007) Keeping up with the E-Times. Chain Store Age, 83, 12-13.

[53] Mayo, P., Donnelly, M.B., Nash, P.P. and Schwartz, R.W. (1993) Student Perceptions of Tutor Effectiveness in Problem Based Surgery Clerkship. Teaching and Learning in Medicine, 5, 227-233. http://dx.doi.org/10.1080/10401339309539628

[54] Delisle, R. (1997) How to Use Problem-Based Learning in the Classroom. Alexandria VA: Association for Supervision and Curriculum Development.

[55] Carruth, J. (2007) Flying High. E-Learning Age, June, 24-25.

[56] Netteland, G., Wasson, B. and Morch, A.I. (2007) E-Learning in a Large Organization: A Study of the Critical Role of Information Sharing. Journal of Workplace Learning, 19, 392-411. http://dx.doi.org/10.1108/13665620710777129 